\title{
Bauhausin moninaiset kaudet
}

Essi Syrén

Wulf Herzogenrath, Das bauhaus gibt es nicht (Berlin: Alexander Verlag), 2019, 152 s.

Bauhausin 100. juhlavuosi sai aikaan aihetta käsittelevien saksan- ja englanninkielisten kirjojen aallon. Lukuisten yleistajuisten taidekirjojen sekä tutkimuksellisemmin painottuneiden teosten lisäksi Bauhaus on noussut esille myös fiktion aiheena esimerkiksi Theresia Enzensbergerin romaanissa Blaupause (2017). Yksi Bauhaus-tutkimukseen liittyvistä teoksista on Wulf Herzogenrathin Das bauhaus gibt es nicht (2019), joka on kokoelma taidehistorioitsija Herzogenrathin eri vuosikymmeninä ilmestyneitä artikkeleita Bauhausista. Vaikka teos on artikkeli- ja sivumäärältään melko suppea, se onnistuu tuomaan yllättävän hyvin esille Bauhausin erilaisia lähtökohtia ja painopisteitä.

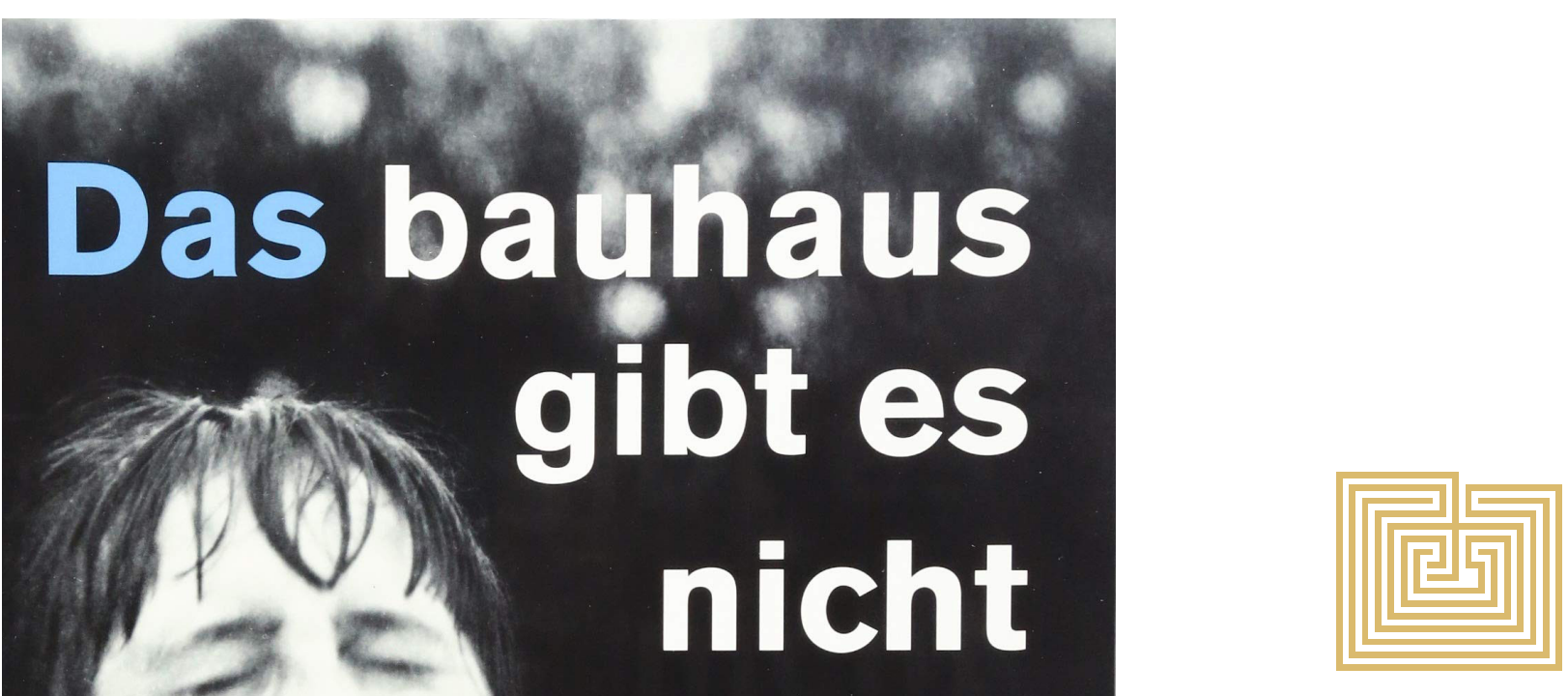


Kirjan provokaatioksi tarkoitettu nimi Das bauhaus gibt es nicht liittyy Herzogenrathin ydinteesiin. Nimi on suoraan käännettynä Bauhausia ei ole, mutta otsikon aloittava saksan kielen määräinen artikkeli das, joka viittaa yhteen määrättyyn kokonaisuuteen, kritisoi kielen tasolla yhdenmukaisuuden ajatusta. Nimen voisi siis kääntää myös Yhtä Bauhausia ei ole, sillä yhden Bauhausin sijaan vuonna 1919 perustetun koulun historia koostui lukuista erilaisista, usein myös ristiriitaisista näkemyksistä arkkitehtuurista, muotoilusta, pedagogiikasta sekä taiteen ja politiikan suhteesta. Herzogenrath siis kritisoi näkemystä, jonka mukaan Bauhaus olisi pelkistettävissä yhteen ominaisuuteen, Bauhaus-tyyliin.

Teokseen valikoidut Herzogenrathin artikkelit ovat vuosilta 1977, 1978, 2009 ja 2010. Kirjan aloittaa johdantoartikkeli, jonka hän on kirjoittanut vuonna 2018 nyt arvioitavaa teosta varten. Hän tarkastelee kanonisoidun tulkinnan taustoja Bauhaus-vastaanoton eri historiallisten tilanteiden näkökulmasta ja keskittyy erityisesti vuonna 1968 järjestettyyn suureen Bauhausin 50-vuotisjuhlanäyttelyyn, joka on vaikuttanut merkittävästi myöhempään vastaanottoon. Saksan liittotasavallan ulkoasiainministeriön rahoittama näyttely kiersi ympäri maailmaa ja keräsi miljoonayleisön. Näyttely vaikutti omalta osaltaan Bauhaus-tyylin käsitteen syntyyn ja yksinkertaisti näin myöhempää tulkintaa koulun taiteellisesta ja yhteiskunnallisesta toiminnasta.

\section{Bauhausin viisi vaihetta}

Teoksen ensimmäinen varsinainen artikkeli "Die fünf Phasen des Bauhauses" on esitelmäkäsikirjoitus Centre Pompidoussa järjestettyä kollokviota varten vuodelta 1978. Artikkelissa Herzogenrath painottaa Bauhausin moninaisia puolia, jotka vaihtelivat kolmen eri johtajan kaudella suunnittelun tavoitteissa, materiaalivalinnoissa, työprosesseissa ja yksittäisten tekijöiden omissa monimuotoisissa lähtökohdissa. Artikkelista muodostuu kirjan ydinteksti, sillä Herzogenrathin muissakin artikkeleissa toistuva keskeinen argumentti Bauhausin monipuolisuudesta tiivistyy teoriaksi 14 vuotta toimineen Bauhausin viidestä eri vaiheesta.

Ensimmäinen, ekspressiivis-individualistinen käsityöläisvaihe ajoittuu Weimarin Bauhausin alkuvuosille 1919-1922. Ensimmäistä maailmansotaa edeltänyt ekspressionismi vaikutti edelleen voimakkaasti saksalaisessa kulttuurissa, mikä näkyi myös Bauhausiin rekrytoitujen opettajien kuten Lyonel Feiningerin ja Paul Kleen taiteessa. Johannes Itten toi Mazdanan -opin myötä myös aikakauden esoteerisia virtauksia Bauhausiin. Gropius antoi vapauksia opettajilleen eikä pyrkinyt määrittelemään kurssien sisältöä, minkä vuoksi vuonna 1922 Willem Huszar kritisoi de Stilj-lehdessä Bauhausia "sattumanvaraiseksi ja oikukkaaksi" (29). Käsityöläisyys ja materiaalien tutkiminen olivat alkuvaiheen keskeisiä arvoja, jotka myöhemmin muokkautuivat teollisen tuotannon mittasuhteisiin.
Toinen, konstruktivistinen vaihe ajoittuu Weimarin ajan kahdelle viimeiselle vuodelle. Herzogenrathin mukaan Bauhausin henkilökunta ja opiskelijat irrottautuivat vuoden 1922 lopussa ja 1923 työssään tunteesta, yksilöllisyydestä sekä ornamentista. Uudet typografiset kokeilut, selkeät muodot ja uudenlainen arkkitehtuuri, joka tiivistyi Georg Muchen suunnittelemassa Haus am Horn -esimerkkitalossa, olivat esillä vuoden 1923 suuressa Bauhaus-näyttelyssä, joka esitteli koulun mestareiden ja oppilaiden tuotoksia.

Bauhausin toiminta oli uhattuna talvilukukaudesta 1924 alkaen ja lopulta uusi koulu avattiin Dessaussa 4. joulukuuta 1926. Herzogenrath ajoittaa Bauhausin kolmannen, funktionaalisesti painottuneen ja teolliseen tuotantoon tähtäävän kauden vuosille 1924-1927, joskin hän myöntää itsekin, että vaiheen ajallinen rajaaminen on muutosten liudentumisen vuoksi hankalaa. Bauhausin muutto Dessaun teollisuuskaupunkiin korosti entisestään teollisen tuotannon merkitystä alkuvuosien käsityöläisyyden sijaan. Esimerkkinä kauden muotoilusta Herzogenrath käyttää Marcel Breuerin putkirunkoista Wassily-klassikkotuolia Clubsessel B 3 (1926), joka on edelleen tuotannossa.

Walter Gropius oli vuoteen 1927 mennessä luonut Bauhausiin haluamansa kaltaisen arkkitehtuuriosaston, jonka johtajaksi tuli Hannes Meyer. Meyer nousi huhtikuussa 1928 Gropiuksen seuraajaksi, jonka kaudella arkkitehtuuri ja sen funktionaalisuus korostui 
entisestään. Herzogenrath ajoittaakin Bauhausin neljännen vaiheen Meyerin johtajakaudeksi 1928-1930. Meyerin pääpyrkimys arkkitehtuurissa oli luoda asuntoja yhteiskunnan vähävaraisille ja hänen myötään politiikka tuli mukaan Bauhausin toimintaan. Oikeistoradikaalien kasvava painostus paikallispolitiikassa lopetti lopulta Meyerin kauden ja vuonna 1931 Bauhausin toiminnan Dessaussa. Viidennessä vaiheessa vuosina 1930-1933 poliittisesti Meyeria neutraalimpi Ludwig Mies van der Rohe jatkoi koulun kolmantena johtajana, joka loi uusia kontakteja teollisuuteen ja yritti pitää toiminnan käynnissä jatkuvasta kansallissosialismin paineesta huolimatta. Berliiniin muuttanut Bauhaus sulki ovensa lopullisesti huhtikuussa 1933 muutama kuukausi kansallissosialistien valtaannousun jälkeen.

Herzogenrathin esittämä jaottelu on perusteltu ja toimii hyvänä argumenttina kirjan ydinteesille, joka vaikuttaa nykykontekstissa yllättävän tuoreelta artikkelin kirjoitusajankohdasta huolimatta. Uudemmassa tutkimuksessa samankaltainen kritiikki yksipuolista Bauhaus-tulkintaa kohtaan on noussut esille muun muassa Bauhaus-arkiston tutkijan Adriana Kapsreiterin Tahiti 8: From Material to Immaterial: Art Historical Practices in the Contemporary World -konferenssissa pitämässä esitelmässä. ${ }^{1}$ Hän kritisoi näkemystä tiukan funktionaalisesta Bauhaus-tyylistä ja nosti sen sijaan esille Bauhausin varhaiskauden esoteerisuuden, ekspressionistiset ideat sekä opetusta leimanneen yhteisölli- syyden, jotka heijastuivat myös Bauhausin myöhempiin vuosiin.

Herzogenrathin sinällään perusteltua jakoa eri kausiin voi toki kritisoida yksittäisten vaiheiden yksinkertaistamisesta, joka on väistämätöntä periodisoinnissa. Lisäksi jaottelussa korostuu voimakkaasti hallinnollinen näkökulma ja kolmen eri johtajan rooli. Johtajat ovat ymmärrettävästi linjauksillaan vaikuttaneet merkittävästi opetukseen, opiskelijavalintoihin ja opettajien rekrytointeihin. Olisi kuitenkin kiinnostavaa, jos Herzogenrath olisi avannut laajemmin myös opiskelijoiden näkökulmaa eri kausina. Kaiken kaikkiaan Bauhausin monimuotoisuuden analysoiminen erilaisten kausien avulla mahdollistaa koulun toiminnan tarkastelun eritellymmin.

\section{Bauhausin ja politiikan jännitteinen suhde}

Herzogenrath käsittelee ansiokkaasti teoksessaan usein huomiotta jäänyttä aihealuetta eli Bauhausin suhdetta Weimarin tasavallan poliittisiin ideologioihin sekä Thüringenin ja Anhaltin osavaltioiden sekä Weimarin ja Dessaun kaupunkien paikallispolitiikkaan. Bauhaus perustettiin huhtikuussa 1919 pian ensimmäisen maailmansodan päättymisen jälkeen ja hieman ennen Versailles'n rauhansopimuksen solmimista. Weimarin tasavallan alkuvuodet olivat taloudellisesti niukat suurten sotakorvausten vuoksi, minkä vuoksi Bauhausin ylläpitäminen pakotti Walter Gropiuksen solmimaan hyvät välit paikallisiin poliitikkoihin. Jo koulun alkuvuosina toiminta oli usein yksittäisten paikallispoliitikkojen äänten varassa. Käytännön realiteeteista huolimatta Gropius pyrki pitämään politiikan etäällä johtamastaan oppilaitoksesta, minkä vuoksi Bauhausissa ei ollut virallisia poliittisia opiskelijajärjestöjä tai muita toimijoita Gropiuksen kaudella. Meyerin kaudella sosialismin merkitys alkoi korostua Bauhaus -arkkitehtuurin taustaideologiana, minkä vuoksi koulu ajautuikin ristiriitoihin paikallistason kansallissosialistien kanssa.

Herzogenrath tarkastelee vuonna 2009 ilmestyneessä artikkelissaan "Fanal einer neuen Zeit" Oskar Schlemmerin Bauhaus-freskoja ja niiden tuhoamiseen liittyviä poliittisia ulottuvuuksia. Schlemmer suunnitteli vuoden 1923 suurta Bauhaus-näyttelyä varten suuria freskoja eri puolille Henry van de Velden suunnittelemaa koulurakennusta (1907-1908). Näyttelyä varten maalatut freskot jäivät esille näyttelyn sulkeuduttua. Samaa tarkoitusta varten tehtyjä Joost Schmidtin reliefejä kuitenkin vahingoitettiin toukokuussa 1924. Talonmiehen kirjeen mukaan syylliset olivat humalaisia opiskelijoita, joskin teolle saattoi olla myös poliittinen selitys, sillä osavaltiovaalien seurauksena nationalistit pääsivät valtaan Thüringenissä helmikuussa 1924. Bauhausin rahoitus puolitettiin seuraavana vuonna, mikä johti päätökseen olla jatkamatta opettajien määräaikaisia suhteita ja lopulta koulun siirtymiseen Dessauhun. Schlemmerin suunnittelemat freskot maalattiin 
lopulta valkoiseksi vuonna 1930 silloisen kansallissosialistien paikallispoliitikko Paul Schulze-Naumburgin päätöksestä (70).

Vaikka Bauhaus suljettiinkin lopullisesti vasta vuonna 1933, Herzogenrath näkee vuoden 1924 tapahtumat enteenä Bauhausin myöhemmistä vuosista. Kansallissosialistit suhtautuivat lähtökohtaisesti hyvin kriittisesti Bauhausiin Gropiuksen poliittisesta neutraaliudesta huolimatta. Meyerin kaudella sosialistinen liikehdintä Bauhausissa lisääntyi, mutta opiskelijakunta oli silti hyvin heterogeenista. Stefan Kraus lainaa teoksen päättävässä artikkelissaan opiskelijan kirjettä vuodelta 1932, jossa kuvaillaan kahden ryhmittymän, kommunistien ja muiden vasemmistolaisten sekä oikeistolaisemman ryhmän välistä jännitettä. Oikeistoon orientoituneiden opiskelijaryhmittymän ideologiat ulottuivat kevyestä konservatismista kansallissosialismiin (140).

Bauhaus on herättänyt poliittisia intohimoja myös koulun sulkemisen jälkeen, mihin Herzogenrath viittaa lyhyesti johdantoartikkelissaan. Analyysia Bauhausin poliittisesta merkityksestä toisen maailmansodan jälkeen olisi ollut kiinnostavaa lukea enemmänkin, mutta aihealue olisi vaatinut teokseen vähintäänkin yhden artikkelin lisää.

\section{Elämää Bauhausissa}

Bauhaus oli näkyvä osa Weimarin ja Dessaun kulttuurielämää ja koulu vaikutti monin tavoin kaupunkien sosiaaliseen todellisuuteen ja katukuvaan. Alun perin vuonna 2010 ilmestyneessä artikkelissaan "Bauhaus Weimar: 1915-1925: international oder 'anational'" Herzogenrath tarkastelee lähemmin koulun toimintaa nationalismin ja 1920-luvun kosmopoliittisuuden ja kansainvälisyyden näkökulmasta. Bauhausin 50-vuotisjuhlanäyttelyn alaotsikoksi oli valittu "german exhibition", joka osoittautuu varsin harhaanjohtavaksi, jos tarkastellaan koulun toimintaa kansainvälisyyden näkökulmasta. Lukuisat opettajat, kuten sveitsiläinen Johannes Itten ja unkarilainen László Moholy-Nagy, kutsuttiin Bauhausin opettajiksi ulkomailta. Myös opiskelijoissa oli paljon nuoria Saksan ulkopuolelta, pääsääntöisesti Keski-Euroopasta. Lisäksi Bauhausin keskeisillä toimijoilla oli yhteyksiä moniin aikakauden taiteellisiin suuntauksiin Saksan ulkopuolella. Wassily Kandinsky loi yhteyden venäläiseen konstruktivismiin, kun taas vuonna 1921 ja 1922 Bauhausissa toiminut Theo van Doesburg toi opetukseen vaikutteita De Stilj -liikkeestä.

Teoksen päättää Stefan Krausin artikkeli arkielämästä Bauhausissa. Koulun toiminnassa korostui voimakkaasti yhteisöllisyys, joka näkyi lukuisissa perinteeksi muodostuneissa juhlissa. Naamiaisilla ja muilla tapahtumilla kuten vuosittaisella leijajuhlalla (Drachenfest) oli myös taiteellisia ja pedagogisia ulottuvuuksia, sillä opiskelijat joutuivat keräämään ja käyttämään arkisia materiaaleja ja tekemään luovia ratkaisuja. Hauskana yksityiskohtana Kraus mainitsee Bauhausin jazzorkes- terin, joka vuosien mittaan kehittyi ja etabloitui niin, että Berliner Zeitung -sanomalehden kriitikko kehui orkesteria parhaaksi kuulemakseen jazzbändiksi (136).

Artikkelien lisäksi teokseen on sisällytetty myös valikoima Bauhausissa opiskelleiden Ruth Hollósin ja Erich Consemüllerin jäämistöistä koottuja aiemmin julkaisemattomia valokuvia. Monet kuvista on otettu naamiaisissa tai muissa juhlissa, mikä kuvastaa hyvin yhteisöllisyyttä. Kuvissa korostuu myös leikkisyys. Kirjan kanneksi valittu valokuva Katt Bothista näyttämässä kieltä kameralle tiivistää hyvin Bauhaus-opiskelijoihin liitetyn riehakkuuden, joka herätti närää erityisesti Weimarin ja Dessaun konservatiivissa piireissä.

Herzogenrathin teos onnistuu antamaan Bauhausista erittäin monipuolisen kuvan vain 152 sivussa. Joitain näkökulmia, kuten Bauhausin vaikutusta taidepedagogiikkaan, olisi voinut syventää, mutta tällöin julkaisu olisi todennäköisesti ollut useamman eri alan asiantuntijan koostama artikkelikokoelma. Herzogenrathin artikkelit muodostavat kirjoitusajankohtien vaihtelusta huolimatta selkeän kokonaisuuden, josta hahmottuu hyvin teoksen ydinteesi: yhden Bauhausin sijaan vuonna 1919 perustettu koulu edustaa lukuisia, usein myös keskenään ristiriitaisia näkökulmia muotoiluun, arkkitehtuuriin ja yhteiskuntaan. 


\section{Endnotes}

Adriana Kapsreiter, "From Immaterial to Material: An Art Historical Genesis of the Bauhaus Design Icons", esitelmä Tahiti 8: From Material to Im material: Art Historical Practices in the Contemporary World -konferenssissa, 28.11.2019.
FM Essi Syrén on taidehistorian väitöskirjatutkija, jonka tutkimuskohteita ovat saksalainen taide, kirjallisuus ja kulttuuri 1900-luvun ensimmäisinä vuosikymmeninä sekä avantgarden ja moderniteetin teoriat.

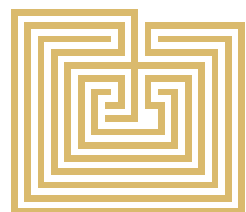

